\title{
Risks of interaction of participants in the labeling (chiping) of goods in order to counter counterfeiting
}

\author{
Vyacheslav Bezdenezhnykh ${ }^{1}$, Diana Arutiunian ${ }^{1}$, and Elena Karanina ${ }^{2,{ }^{*}}$ \\ ${ }^{1}$ Financial University under the Government of the Russian Federation, 49, Leningradsky Prospekt, \\ 125993, Moscow, Russia \\ ${ }^{2}$ Vyatka State University, 36, Moskovskaya St., 610000, Kirov, Russia
}

\begin{abstract}
The importance of research is determined by the increasing need for identification and authentication of goods in order to ensure country economic resilience through counterfeit deterrence. In this article based on relationship practice of labelling (chipping) process participants, interest harmonization proposals for the participants are justified in order to prevent and deter counterfeit and falsified goods. The purpose of the work is to reduce the risks through improving interchain relationship between labelling (chipping) process participants in the fight against illegal trafficking in goods as a procurement mechanism of State economic resilience through considering the problems in relationship between chipping process participants and possible risks in the process of their communication, proposing measures to minimize risks in the interaction process of the participants and characterizing the measures proposed. The object of the research is technological methods of protection against counterfeit. The subject of the work is a relationship system of interest harmonization and communication improvement between producers using product chipping technology (RFID, Data Matrix), labelling operator, government and consumers during counterfeit and falsified good combat. Methodology: the study used general scientific methods of analysis and synthesis, a method of modeling and analogy, as well as a special statistical and economic method.
\end{abstract}

\section{Introduction}

In the world there is still no unified system of labeling and traceability that would cover all trading groups in the market. As a rule, "local" solutions are used that apply to specific product groups, more often to excisable ones. But there are general principles and stages, which will allow us to develop common analysis approaches and proposals for solving the questions posed in the preamble.

It should be noted that the first "traceability" systems were most developed in SouthEast Asia, which accounts for almost $80 \%$ of the total global turnover of counterfeit goods. However, their implementation is segmented, and often the initiators of the promotion of

* Corresponding author: kafinanc@yandex.ru 
such infrastructure are large concerns that do not like the fact that left-hand products are sold under their brand. An illustrative example is the Federation of the German automobile industry, which defines the marking standards for the automotive industry and the production of spare parts. Traceability is considered an important security tool in the EU because of the global flow of goods produced by national enterprises and coming from all over the world [1]. In case of violation of mandatory procedures by searching for and finding the cause, it is possible to limit the amount of damage and inform consumers with reliable data about the origin of the purchased product [2]. Moreover, since the information of each individual enterprise against the background of the industry structure is insufficient, a system is used that covers all participants in the planning, management and control of trade [3]. The sanctions for the lack of a "traceability" system are quite palpable. Currently, in Russia, the Federal tax service is responsible for working out the principles and rules of goods chipping systems, which quite successfully applies the possibilities of electronic technologies in the disclosure of illegal business schemes in the Russian Federation. To date, the Federal tax service has made great progress in the use of electronic technologies. In particular, one of the achievements of the Federal tax service is the creation of a database of legal entities that allows any organization to check contractors for integrity.

Trading activities in Russia are regulated by Federal law No. 381-FZ of 28.12.2009. The law gives the Russian Government broad powers. This includes the approval of the list of products subject to mandatory labeling and the rules for chipping products (p. 3. 1 part 1 of article 5 of the Federal law No. 381-FZ.). The model of the marking system was approved by Government Order No. 791-R of 28.04.2018. The list of goods is fixed by Government Order No. 792-R of 28.04.2018. The regulation on conducting an experiment on marking shoes is fixed by Government Decree No. 620 of 30.05.2018. The experiment is carried out with 01.06.2018 for 30.06.2019 year. Additionally, Guidelines were developed for the participants of the experiment (adopted by Ministry of industry and trade of the Russian Federation 03.09.2018). The rules for chipping tobacco products are fixed by Government Decree No. 224 of 28.02.2019. The document specifies the terms for registering producers, importers and sellers in the GIS and entering data on tobacco turnover.

The rules for marking products with identification tools were approved by Government Decree No. 515 of 26.04.2019. The regulatory act also contains a Provision on the monitoring system for product turnover. Tariffs for the provision of services for the provision of marking codes are fixed by Government Decree No. 577 of 08.05.2019. However, in the implementation of the chipping products complex risk issues arise and require additional research.

Despite some differences, in general, the understanding of the need to conduct product chipping as a measure to counteract counterfeit production coincides in foreign and Russian practice. The most common issues of study and implementation are identified. At the same time, issues related to the need to regulate the conflict of interests of participants in this sphere of control and market regulation measures remain unexplored [4]. If these issues are not addressed, the effectiveness of the work carried out and measures to control the promotion of products from the manufacturer to the consumer will remain low.

The process of labelling goods includes lots of stakeholders: producers, consumers, regulators, «chipping» technology owners («chipping» operators), supervisors responsible for process establishment of identification and authentication of goods and others. Such relationship may be based on the diverging interests among different groups of participants, that may lead to a decline in the efficiency of preventing the counterfeit and falsified good production.

Thus, the producers themselves do not want the cost increase due to additional expenditures on «chipping». As for expensive products, such expenditures may have a little 
impact on the final price (e.g., fur, jewelry, weapons and etc.). However, for relatively lowpriced products, but quite widespread ones (foodstuffs, medicines, constructional materials and tools, etc.), labelling costs may increase the price of these products by more than 10 $15 \%$.

It is important for consumers to get quality products from the producer in accordance with the technology, but without over-pricing, that means at an adequate price. As for supervision and oversight authorities, it is important to disseminate labelling methods widely, both from the prism of combating the shadow economy and from the prism of fighting against corruption, illicit financial flows and terrorist funding. Also, other market players are interested in this process: financial and credit institutions, insurance companies, media organizations, trade unions, company partners and etc. As for state institutions, it is important to develop a civilized market, increase the taxable base, develop corporate social responsibility, form a business community with a higher culture functioning. At the same time, regarding the overall positive assessment of the need for product labeling, producers do not want their costs to increase; consumers are against the price increase; companies, involved in the process of labelling, want in every possible way to ensure economic efficiency of their businesses, which affects the interests of the two previously mentioned market participants; as for the supervisory, there is an urgent necessity for the possible adjustment of market conditions, accurate information about the product on its way from raw materials to the end-consumer and etc. Thus, there is a pressing problem requiring urgent solution, without which, on the one hand, the development of quality products in the Russian market is impossible and, on the other hand, so is strengthening of coherent policies for combating illicit financial flows and terrorism funding.

In order to clarify the definitions, it should be noted that the concepts of "counterfeit" and "falsified goods", according to the Federal Law "On Quality and Safety of Foodstuffs" and the Civil Code of the Russian Federation, are not the same, but in this article they are considered to be analogous terms as a matter of mechanisms for counteracting their proliferation.

\section{Materials and Methods}

In the world there is still no unified system of labeling and traceability that would cover all trading groups in the market. As a rule, "local" solutions are used that apply to specific product groups, more often to excisable ones. But there are general principles and stages, which will allow us to develop common analysis approaches and proposals for solving the questions posed in the preamble.

The process of labelling goods includes lots of stakeholders: producers, consumers, regulators, «chipping» technology owners («chipping» operators), supervisors responsible for process establishment of identification and authentication of goods and others. Such relationship may be based on the diverging interests among different groups of participants, that may lead to a decline in the efficiency of preventing the counterfeit and falsified good production.

Thus, the producers themselves do not want the cost increase due to additional expenditures on «chipping». As for expensive products, such expenditures may have a little impact on the final price (e.g., fur, jewelry, weapons and etc.). It is important for consumers to get quality products from the producer in accordance with the technology, but without over-pricing, that means at an adequate price. As for supervision and oversight authorities, it is important to disseminate labelling methods widely, both from the prism of combating the shadow economy and from the prism of fighting against corruption, illicit financial flows and terrorist funding. Also, other market players are interested in this process: financial and credit institutions, insurance companies, media organizations, trade unions, 
company partners and etc. As for state institutions, it is important to develop a civilized market, increase the taxable base, develop corporate social responsibility, form a business community with a higher culture functioning. At the same time, regarding the overall positive assessment of the need for product labeling, producers do not want their costs to increase; consumers are against the price increase; companies, involved in the process of labelling, want in every possible way to ensure economic efficiency of their businesses, which affects the interests of the two previously mentioned market participants; as for the supervisory, there is an urgent necessity for the possible adjustment of market conditions, accurate information about the product on its way from raw materials to the end-consumer and etc. Thus, there is a pressing problem requiring urgent solution, without which, on the one hand, the development of quality products in the Russian market is impossible and, on the other hand, so is strengthening of coherent policies for combating illicit financial flows and terrorism funding.

In order to clarify the definitions, it should be noted that the concepts of "counterfeit" and "falsified goods", according to the Federal Law "On Quality and Safety of Foodstuffs" [2] and the Civil Code of the Russian Federation [1], are not the same, but in this article they are considered to be analogous terms as a matter of mechanisms for counteracting their proliferation.

As mentioned above, today one of the most technologically promising and evolving methods of combating counterfeiting is the use of hi-tech means of produce protection, in other words, "chipping" the goods. This allows to track product status across the upstream, midstream and downstream. The objectives of labelling, as it was pointed out, are optimization of business processes, establishment of a transparent production chain of goods for all market participants (producers, consumers, the state) in the fight against counterfeiting. However, the implementation of technologies into business is fraught with a multitude of threats, risks and expenses.

Firstly, it is assumed that informatization and computerization of production processes will optimize operations and create a direct interaction channel between private business and the state, that will make the information exchange process cheaper and reduce time expenditures. However, after the implementation of certain production standards, in general (according to statistics), the number of regulatory authority inspections does not decrease, inversely, they grow. The struggle against bureaucratic domination, despite numerous reforms, does not yield results. From the economic point of view, the maintenance of regulatory authorities leads to additional costs, as well as any inspections, which pull the producer off of the current activities, that is why direct losses appear. Also, in the process of inspections there are conditions for possible corruption risk emergence. Initial support and control of the chipping technology installation and implementation by CDTA's specialists will help to reduce economic costs of inspections.

Secondly, we will consider possible threats to the financial side of the labelling process. The main CDTA's source of income is an emission of product labelling codes setting different prices for the code in dependence to a product group (for example, 50 kopecks Russian currency which is equal to a half of Russian ruble - per package of milk), free of charge - for vital essential and necessary drugs and medical sundries, the price of which does not exceed 20 rubles. But the presence of monopoly leads to monopoly prices. It will be difficult to allocate cost and profit components. Also, the CDTA plans to sell these analytics. It's assumed, there should be strict control over the published information in compliance with producers' consent. In addition, a supervisory and monitoring intermediary should be appointed and have special powers to regulate the situation.

Thirdly, the CDTA has been declared the single labelling operator in the market. Thus, it is entirely possible that the CDTA makes more profit of its policy than the other labeling process participants, but if the producers, in turn, are not satisfied with the CDTA's policy, 
they do not have the ability to choose another operator, in simple terms, no other operator is in the market, or to abandon the labelling, as they are obliged to chip the products. Moreover, by 2024 the government plans to "chip" all categories of goods, and this problem may become quite acute $[5,7]$. Therefore, it is necessary to control the labelling conditions, democratic relationship between producers and operator and balanced cooperation conditions through the formation of a state body and producers associations on the principle of trade unions.

\section{Results}

Nowadays, modern technologies are the key components of everyday life of many people, and the term informatization has been used as a guarantee of economic and social development. Full-scale implementation of information technologies has led to the fact that the human environment is filled with different technical devices, the work function of which is impossible without the various means of labelling.

Labelling (chipping) tools allow to keep track of goods and service payments and to give/block information access, that is real through the use of RFID, Data Matrix and other technologies.

Thus, chipping technology is a powerful mechanism to combat serious social threats: the production and sale of counterfeit goods, money laundering, economic crime, corruption and harm to the public health.

Losses from the lack of widespread practice of product chipping for the Russian economy are significant (According to the Ministry of Industry and Trade, the share of illicit goods in various sectors of Russia ranges from 20 to $50 \%$. In monetary terms, this is more than 2 trillion rubles, or about $15 \%$ of the revenue of the Russian federal budget in 2018. "Roscachestvo" cites roughly the same data, according to estimates of which counterfeit reaches $30 \%$ in different sectors of the domestic economy. Source: https://www.26-2.ru/art/355237-obyazatelnaya-markirovka-tovarov). So, as an example, data is presented for individual items of goods in table 1.

Table 1. Data on the assessment of probable losses due to the lack of chipping for certain groups of goods in Russia in recent years (2016-2018) (Source: compiled by the author according: https://news.rambler.ru/other/40011012-chem-grozit-povalnaya-markirovka-tovarov-radiochipamimechenye-podguzniki/).

\begin{tabular}{|c|c|c|}
\hline No & $\begin{array}{l}\text { Types of } \\
\text { products }\end{array}$ & Assessment of probable losses \\
\hline 1 & $\begin{array}{l}\text { Clothes and } \\
\text { shoes }\end{array}$ & $\begin{array}{l}\text { According to the Union of Textile and Light Industry, the turnover of } \\
\text { the illegal clothing and footwear market in Russia is } 35 \% \text { of the entire } \\
\text { retail market, which is } 910 \text { billion rubles a year. } 65 \% \text { of all children's } \\
\text { shoes are fake. }\end{array}$ \\
\hline 2 & Baby products & $\begin{array}{l}\text { According to the Association of enterprises for the industry of } \\
\text { children's goods (AIDT), only in } 2016 \text { the share of counterfeit goods in } \\
\text { Russia amounted to more than } 40 \% \text {. There are frequent cases when } \\
\text { toxic substances were found in children's products: lead, benzene and } \\
\text { mercury, according to the association. }\end{array}$ \\
\hline 3 & Pharmaceuticals & $\begin{array}{l}\text { According to the Moscow Department of Health, approximately } 7 \% \text { of } \\
\text { all drugs in the capital is substandard, either produced in violation or } \\
\text { expired. It is not yet known exactly how the drugs will be labeled - } \\
\text { using RFID tags or cheaper Data Matrix tags based on a two- } \\
\text { dimensional barcode, but, according to media reports, the pilot project } \\
\text { was launched in January 2017. Six Russian and foreign companies have }\end{array}$ \\
\hline
\end{tabular}




\begin{tabular}{|l|l|l|}
\hline & & $\begin{array}{l}\text { confirmed their participation in it: R-Farm, Biokad, Katren, } \\
\text { AstraZeneca, Boehringer Ingelheim and Stada CIS. They are already } \\
\text { labeling some of their products *. }\end{array}$ \\
\hline 4 & $\begin{array}{l}\text { Auto and } \\
\text { aviation parts }\end{array}$ & $\begin{array}{l}\text { Annually, trade in counterfeit goods brings Russian automakers losses } \\
\text { in the amount of five to eight billion rubles. But the bill, after all, goes } \\
\text { not only for money, but also for thousands of lives. Fake details are one } \\
\text { of the most common causes of disasters with many casualties. In } \\
\text { addition, Russia today suffers large image losses in the foreign market } \\
\text { due to cases of counterfeit use in export-oriented products. }\end{array}$ \\
\hline $\begin{array}{l}\text { * Chips on drugs have opponents. According to the Association of } \\
\text { Russian Pharmaceutical Manufacturers (ARFP), RFID tags can be } \\
\text { expensive for pharmacological companies: additional equipment for } \\
\text { production and warehouses will be required, and production costs may } \\
\text { increase. In addition, RFID tags cannot be applied to foil blisters in } \\
\text { which 80\% of the drugs are packaged, or to gel solutions. There are } \\
\text { also no studies on how such labels affect drug quality. }\end{array}$ \\
\hline
\end{tabular}

Continuing the analysis of the issues of assessing the possible shortcomings of microchips in 2019-21 years. It can be noted that this will inevitably affect wholesale and retail prices. Entrepreneurs will have to bear the following costs, which will affect the cost of goods sold:

- for the manufacture of electronic digital signature, if the keys were not received earlier;

- for connection and maintenance in the "Marking" system (in addition to a one-time connection fee, annual maintenance service fees must also be paid);

- for the manufacture of each unique chip (since they cannot be reprogrammed and reused, these costs will be constant).

For large businesses, such costs may not be significant in the total turnover, but they will still be included in the cost of goods. For small and medium-sized businesses, these costs will be significant and constant. For these reasons, price increases are unlikely to be avoided, since the state does not provide any measures to compensate for additional costs for entrepreneurs.

It is also necessary to consider issues of liability for violations of the law on the chipping of goods. The requirement for mandatory chipping should be observed by manufacturers and sellers working in the domestic market. If the chipping was done in violation of the law, including with unregistered codes, the goods are considered unmarked. In case of violation of the requirements of the law, the punishment for citizens, legal entities and individual entrepreneurs will fall under Art. 15.12 Administrative Code:

- production of goods without marking, or in violation of the order of its application - a fine of 50 to 100 thousand rubles (to enterprises);

- a similar violation in the sale, storage, transportation or purchase of goods for resale a fine of 2 to 4 thousand rubles (for citizens), from 50 to 300 thousand rubles (to legal entities);

- production of alcohol or tobacco without identification means - a fine from 100 to 150 thousand rubles (to legal entity);

- turnover of alcohol and tobacco without labeling - a fine of 4 to 5 thousand rubles (for citizens), from 200 to 300 thousand rubles (to enterprises).

The specified sanctions are applied for each revealed fact of violation. Also, article 15.12 of the Code of Administrative Offenses of the Russian Federation provides an additional measure of influence against violators - forced confiscation of goods from 
circulation. Confiscation will be applied at the same time as a fine. All confiscated products are subject to destruction without payment of compensation to the entrepreneur.

Chipping disadvantages are often the result of advantages. According to the chip, you can find out the history of the product and the manufacturer. But a hacker can quietly slip a scanner, read a code, clone a chip. In this case, the hacker can freely manipulate information. Of course, the chips are protected by cryptography. But experts keep finding vulnerabilities in this defense. Keeping accounts on social networks is also not always a good idea. The stores already have special scanners that track customers by MAC address in their mobile phones. In the case of the chip, it will be possible to discreetly track not only the hardware number, but also gain access to the name, place of work, etc. The idea of storing documents in electronic form, and for access to use the chip also has one significant drawback. If a failure occurs on the state database, then his identity will simply disappear and nothing can be proved. There is no home, no money, no passport in the database; there is nothing to restore. This problem relates not only to the topic of product chipping, but to the global topic of digitalization of the economy and society.

The scale of these threats is particularly high for low-income countries, hitting tens of percent of the country's GDP. At the same time, the falsified goods can be produced in other countries, inside the country or be imported [1]. It should be emphasized that even in countries with high income-per-capita level counterfeit penetrates the market, having a price competitive advantage or solving the problems of illegal money laundering. This determines the relevance of the problem for all countries. At the moment, the State, represented by its institutions, and businesses have been combating counterfeiting with classical methods (strengthening of customs control, using international and national product standards and etc.). But it is not enough and the range of measures, mechanisms and tools is constantly expanding: technical means of countermeasures, particularly «chipping» (Data Matrix and RFID) technology, are being used [2]. The operator of the monitoring information system is the CDTA (the Center for Development of Advanced Technologies (In Russian: "Centr razvitiya perspectivnyh tehnologiy") [4, 5].

In Russia, compulsory labeling will continue in 2020 and subsequent years. Earlier, two types of products were subjected to obligatory labeling - alcohol and fur products. Information on alcohol is collected by the Unified State Automated Information System (EGAIS) under the leadership of the Federal Agency for Alcohol Control. With the help of the Marking information system, fur products are monitored by the tax authorities themselves. Decree of the Government of the Russian Federation of April 28, 2018 No. 792-r and Decree of the Government of the Russian Federation of February 28, 2019 No. 224 tell us that in 2019 the list of marked ones was replenished with such products as: perfumes and eau de toilette; pneumatic rubber tires and tires; knitted women's blouses, blouses and blouses; outerwear; linen (bedding, dining room, toilet, kitchen); cameras, flash units. Since March 01, 2020, footwear has been joining the above products (Order of the Government of the Russian Federation dated April 28, 2018 No. 792-r and Resolution of the Government of the Russian Federation dated 05.07.2019 No. 860). Also, in 2020, it is planned to oblige to label medicines, beer and milk (terms have not yet been determined). Until the end of 2021, Russia proposes to introduce a system for marking cattle, horses, deer, goats and sheep. The aim of this project is to trace the path of meat products from the farm to the goods on the counter. By 2024, the monitoring system according to the plan should cover all possible goods in the Russian market. Given the inevitability of such processes, in our opinion, one more important aspect should be taken into account, which was not discussed in scientific studies. In the process of chipping goods and the subsequent operation of the entire system, a conflict of interest arises for all interested parties. This conflict gives rise to a set of possible risk situations that can reduce the quality of the work involved in organizing the chipping of various types of goods and thereby lead to the losses 
indicated in the preamble of the article, as well as debugging and functioning of the entire system in Russia.

\section{Discussion}

Labelling with Data Matrix and RFID technologies and the creation of a product traceability system is an advanced anti-counterfeit solution. However, such solution to the problem leads to a number of related problems and threats that pose possible risks to business-CDTA relationship. Already today, solution-seeking is necessary, because by the moment of full-scale product chipping in 2024 it is highly probable to be loaded with successive problems and hurryingly search for additional risk management resources. To solve the above-mentioned issues, it is proposed to create two institutional bodies.

The first one is common authority created on voluntary basis and consisting of producers in the form of self-regulating organizations or trade unions. The purpose of this body is to observe democratic (this concept requires additional interpretation and is developed by the producers' community itself) labelling conditions for producers, to rate the win-win relationships between CDTA and producers and report controversial issues of CDTA's activity to a special department, described below. This authority is expected to be funded through minimal formal contributions from the participants, the establishment time of the body will take about six months, as the creation process involves the description of certain regulations, participation rules, membership in the association, and the statute.

The second one is a public body which should be an administrative and formal in nature, possibly, established in composition with the Ministry of Industry and Trade (Minpromtorg) as a separate department for control and supervision of chipping process participants. At the same time, in connection with this new public body, Community Board of consumers (people's control) should be established in order to evaluate the quality of the adopted policy from the people's point of view. The function of this department is supposed to be an inspection of labelling equipment and its embeddings in the production processes; assistance in solving the producers' association issues (the organizational principle is described above); censorship of analytical reviews for public use and etc. The authority is expected to be funded by government, producers and labelling operator. The budget amounts can be calculated on the risk assessment basis in one or another sphere of the labelling process implementation [8]. The agency establishment will not take a long time, presumably it takes about six months, as it is only needed to document the authority's formation principles and instructions and determine the source of funding for its activities.

At least once a year it is necessary to hold a meeting under the aegis of these two bodies in order to discuss the results of cooperation in the field of chipping for eliminating possible failures and procedural violations and improving the effectiveness of the work carried out. At the first stage it is desirable to attract top public officials to the work of these new structures. According to the experience of many countries (the USA, Germany, France, Finland, Russia, etc.) it is known that it helps to jump-start the work.

Generally, implementation of such simple steps as creating regulators of relations between the chipping process participants, that, in its own way, is relatively low cost (the most significant costs of organizing and conducting the labelling process are borne by commercial structures) and can be quickly proceeded, can reduce the risks of shifting to high-tech forms of safeguarding from counterfeiting and falsified goods in various sectors of the economy.

Important elements of the plan in this process should be a public discourse of the issues in media and transparency of new proposed authorities and their follow-up activities. In our view, this will also stimulate the growth in the anti-counterfeiting education among the population and more active integration of it into real counteraction to counterfeiting and 
falsification. These issues have to be declared in the legal documents of these institutes as an obligatory aspect of their work.

\section{Conclusion}

Thus, the following conclusions can be made. In 2024, Russia will create a unified system for the continuous labeling of all goods without exception: from cigarettes and alcohol to diapers and baby food, in order to cope with counterfeit products, the volume of which in our country, depending on the industry, is $20-50 \%$. The analysis of this problem showed that the proposed innovation has both pluses and minuses. These findings confirm the opinion of some experts on this topic [12]. There is a danger that its implementation will lead to significant state costs and seriously hit the pockets of consumers.

The Russian authorities have recently been attentive to the issue of introducing modern equipment in a wide variety of industry segments and in everyday life. In January 2020, the new government even created a special Ministry of Digital Development, transformed from the Ministry of Communications. It will devote its activities to the formation of a unified interface and standard of electronic services, which will help Russians remotely receive public services. The "traceability" of goods is now universally considered an important security tool due to the global flow of goods produced both by national enterprises and from all over the world. In case of violation of the mandatory procedures by searching and finding the reason, it becomes possible to limit the amount of damage and inform consumers with reliable data on the origin of the purchased goods. Moreover, since the information of each individual enterprise against the background of the sectoral structure is not enough, a system is applied that covers all participants in the planning, management and control of trade.

Meanwhile, not everyone is sure that digital technologies will be workable and convenient to use. Moreover, there is a likelihood that their implementation will lead not to cost savings, but to additional financial costs of both the state and ordinary consumers. The study showed some reasons why, after tightening trade regulation, the problem of the presence of counterfeit goods on the domestic market will not be resolved [8]. In fact, the state introduces a new and, it is important to note, private tax (the operators of administration and management of the labeling process are non-state companies) on the quality of purchased goods. Although manufacturers and retailers will have to pay it, it will transfer retail prices to ordinary consumers. "The costs of producers will be paid by ordinary citizens, who will pay extra money for each item," says T. Shokareva, President of the Direct Selling Association [13]. Taking into account the conflict of interests of all participants in order to achieve the goal of reducing counterfeit in the Russian markets to an acceptable level is a prerequisite for the successful solution of the whole complex of problems.

The use of advanced technologies (RFID - and Data Matrix - technologies) in the fight against counterfeiting in order to ensure economic security and reduce the level of shadow economy in Russia in addition to the positive result of implementing the labelling technology is fraught with a number of possible institutional threats and risks: participants' (manufacturers, consumers, the state, the operator of chipping) interests mismatch.

In order to improve the chain of interaction between labelling process participants, a number of measures were proposed to neutralize the problem: the creation of a manufacturers' association on voluntary basis in order to assess the mutual benefits of cooperation between participants, the formation of a coordinating department in composition with the Ministry of Industry and Trade for the supervision over CDTA's activities and, also, the involvement of the public in the situation estimate in the field of product labelling. 
Due to the fact that the measures are not very costly in terms of organization, economy and technology, they can be implemented quickly and help to control the current labelling market and avoid deeper production problems. There is also an additional indirect economic effect through reducing control structures and improving market competition, so that it facilitates the inclusion of market-based price regulators.

\section{References}

1. C. Loebbecke, Bled e Conference 42 (2005)

2. W. Roy, RFID Explained: A Primer on Radio Frequency Identification Technologies (Morgan \& Claypool Publishers, 2006)

3. Z. Ton, V. Dessain, M. Stachowiak-Joulain, RFID at METRO Group (Harvard Business School, 2004)

4. K. Dowd, The Analytics of Risk Model Validation. A volume in Quantitative Finance, 45-58 (2008)

5. S. Lahiri, RFID. Introduction guide - the RFID Sourcebook (Kudits-Press, 2007) ISBN 5-91136-025-X

6. M. Bkhubtany, S. Moradpour, RFID Field Guide: Deploying Radio Frequency Identification Systems (Alpina publisher, Moscow, 2007) ISBN 5-9614-0421

7. Wei Liang, Songyou Xie, Jing Long, Kuan-Ching Li, Keqin Li, Information Sciences 503, 129-147 (2019)

8. Tao Cheng, Li Jin, Analysis and Simulation of RFID Anti-collision Algorithms (School of Electronics and Information Engineering, Beijing Jiaotong University, 2018)

9. Wenjie Ruan, Quan Z. Sheng, Lina Yao, Xue Li, Lei Yang, Journal of Network and Computer Applications 1041.5, 78-96 (2018)

10. K. Finkenzeller, RFID reference (Dodeka-XXI Publishing house, Moscow, 2008) ISBN 978-5-94120-151-8.9.

11. M. Vlasov, RFID: 1 technology-1000 solutions: Practical examples of using RFID in various fields (Alpina Publisher, Moscow, 2014) ISBN 978-5-9614-4879-5.

12. https://www.26-2.ru/art/355237-obyazatelnaya-markirovka-tovarov

13. https://news.rambler.ru/other/40011012-chem-grozit-povalnaya-markirovka-tovarovradiochipami-mechenye-podguzniki/ 